\title{
Protective cellular immune response against hepatitis $C$ virus elicited by chimeric protein formulations in BALB/c mice
}

\author{
Santa Olivera ${ }^{1}\left(\mathbb{D} \cdot\right.$ Angel Perez $^{1} \cdot$ Viviana Falcon $^{2} \cdot$ Dioslaida Urquiza $^{3} \cdot$ Dagmara Pichardo $^{3} \cdot$ Gillian Martinez-Donato $^{1}$
}

Received: 13 May 2019 / Accepted: 8 November 2019 / Published online: 3 February 2020

(c) Springer-Verlag GmbH Austria, part of Springer Nature 2020

\begin{abstract}
The eradication of hepatitis $\mathrm{C}$ virus (HCV) infection is a public health priority. Despite the efficiency of treatment with direct-acting antivirals, the high cost of the therapy and the lack of accurate data about the HCV-infected population worldwide constitute important factors hampering this task. Hence, an affordable preventive vaccine is still necessary for reducing transmission and the future disease burden globally. In this work, chimeric proteins (EnvCNS3 and NS3EnvCo) encompassing conserved and immunogenic epitopes from the HCV core, E1, E2 and NS3 proteins were produced in Escherichia coli, and their immunogenicity was evaluated in BALB/c mice. The impact of recombinant HCV E2.680 protein and oligodeoxynucleotide $39 \mathrm{M}(\mathrm{ODN} 39 \mathrm{M})$ on the immune response to chimeric proteins was also assessed. Immunization with chimeric proteins mixed with E2.680 enhanced the antibody and cellular response against HCV antigens and chimeric proteins. Interestingly, the combination of NS3EnvCo with E2.680 and ODN39M as adjuvant elicited a potent antibody response characterized by an increase in antibodies of the IgG2a subclass against E2.680, NS3 and chimeric proteins, suggesting the induction of a Th1-type response. Moreover, a cytotoxic T lymphocyte response and a broad response of IFN- $\gamma$-secreting cells against $\mathrm{HCV}$ antigens were induced with this formulation as well. This $\mathrm{T}$ cell response was able to protect vaccinated mice against challenge with a surrogate model based on HCV recombinant vaccinia virus. Overall, the vaccine candidate $\mathrm{NS} 3 \mathrm{EnvCo} / \mathrm{E} 2.680 / \mathrm{ODN} 39 \mathrm{M}$ might constitute an effective immunogen against HCV with potential for reducing the likelihood of viral persistence.
\end{abstract}

\section{Introduction}

Hepatitis $\mathrm{C}$ virus infection is a global health problem. Currently, over 150 million of the world's population are chronically infected [1]. The current treatment based on secondgeneration direct-acting antivirals (DAA) has managed to reduce side effects and the time of treatment and has led to the decrease of HCV RNA to undetectable levels 3 months

Handling Editor: Tim Skern.

Santa Olivera

santa.olivera@cigb.edu.cu

1 Hepatitis C virus Department, Center for Genetic Engineering and Biotechnology, Avenue 31, P.O. Box. 6162, Havana 610600, Cuba

2 Microscopy Department, Center for Genetic Engineering and Biotechnology, Avenue 31, P.O. Box. 6162, Havana 610600, Cuba

3 Animal Care Facility, Center for Genetic Engineering and Biotechnology, Avenue 31, P.O. Box. 6162, Havana 610600, Cuba after the end of therapy in more than $90 \%$ of patients [2-4]. However, DAA treatment alone is not sufficient to stop hepatitis $\mathrm{C}$ transmission. The highest prevalence and incidence of hepatitis $\mathrm{C}$ lays on developing countries with limited access to these expensive therapies. Also, the early diagnosis of this silent disease is hampered by poor implementation of screening methods; it is estimated that only $5 \%$ of $\mathrm{HCV}$ infections are diagnosed globally [5]. In addition, this treatment does not protect against re-infection in high-risk population sectors such as people who inject drugs. DAAs have still several challenges to overcome in the design of effective therapies for the treatment of HCV genotype 3 [6] and patients with chronic kidney disease (reviewed in reference 7). Hence, the development of a vaccine against hepatitis $C$ is still a public health necessity.

Despite decades of research, there is still no licensed preventive vaccine available. Hepatitis $C$ virus is a challenging pathogen, mainly due to its heterogeneity and its tendency to develop escape mutations. Also, there is no feasible animal model that supports infection, and our knowledge of immunological correlates of viral clearance is still limited. 
However, evidence from several clinical trials and studies of individuals with spontaneous clearance of infection suggest that an effective HCV vaccine should induce a multispecific, long-lasting, and vigorous cellular immune response, including both $\mathrm{CD}^{+}$and $\mathrm{CD}^{+}{ }^{+} \mathrm{T}$ cells, as well as a crossneutralizing antibody (NAb) response against the HCV envelope proteins [8-10].

There are mixed opinions regarding the contribution of NAbs in the resolution of acute infections, since subjects with primary hypogammaglobulinemia can resolve it [11]. Also, it has been observed that acutely infected patients manage to clear HCV infection before the establishment of a neutralizing antibody response [12]. However, in several studies, high titers of Abs against the E1 and E2 envelope glycoproteins have been associated with spontaneous clearance of HCV infection [13-15].

The cellular immune response has been the main target of numerous immunization approaches, since spontaneous $\mathrm{HCV}$ clearance is associated with potent, broadly directed, and long-lasting anti-HCV $\mathrm{T}$ cell responses [8]. Also, a rapid drop in viremia that is observed in most humans and chimpanzees during acute infections is kinetically related to the onset of virus-specific T-cell immunity (reviewed in reference 16). In practice, although several vaccine strategies have been shown to reduce viremia after HCV challenge in chimpanzees, no evidence of a clinical impact has been shown in human trials. Currently, a promising vaccine candidate based on a recombinant chimpanzee adenoviral (ChAd3) vector and a modified vaccinia Ankara vector (MVA) coding for non-structural viral proteins is being tested as a preventive approach in high-risk volunteers. However, this strategy previously failed to restore the $\mathrm{CD} 4^{+} \mathrm{T}$ cell response in a study with chronic HCV patients [17]. Taking into account this new knowledge about HCV infection, the use of a prophylactic vaccine might be a better way to significantly reduce $\mathrm{HCV}$ transmission.

Considering the great diversity of available methodologies for vaccine development, the use of recombinant proteins could be an attractive approach, since it allows a wide range of innovation in matter of antigen design. Also, these proteins are generally highly purified and consequently very safe [18]. A downside is the low immunogenicity of recombinant proteins, which can be solved by combining them with the appropriate delivery system/adjuvant for enhancing and directing the immune response. An attractive adjuvant platform that is being developed consists of synthetic oligodeoxynucleotides (ODNs) containing unmethylated $\mathrm{CpG}$ motifs. These molecules trigger cells that express Toll-like receptor 9 (including human plasmacytoid dendritic cells and $B$ cells) to mount an innate immune response characterized by the production of $\mathrm{T}$ helper 1 (Th1) and proinflammatory cytokines, making them suitable for vaccines against viral infections [19]. In addition, these adjuvants can be used intranasally and are among the few that can be administered by this route [20].

An interesting and low-cost alternative for protein vaccine candidates could be the design of chimeric proteins in which several viral antigens are combined in a single protein. There are a few immunization studies based on chimeric proteins against $\mathrm{HCV}$ in which chimeric subviral particles containing $\mathrm{HBV}-\mathrm{HCV}$ envelope proteins were designed to induce NAbs [21]. In another example, hepatitis B virus (HBV) surface antigen was fused to the HCV core protein in the context of a DNA vaccine for enhancing cellular and cytotoxic T-lymphocyte (CTL) responses against the HCV core protein [22].

Taking into consideration all this previous knowledge, we have designed chimeric proteins encompassing epitopes from HCV structural antigens and non-structural protein 3 (NS3) derived from a $1 \mathrm{~b}$ genotype Cuban isolate, including conserved epitopes specific for T and B lymphocytes. With this approach, we expected the induction of both neutralizing antibodies and T-cell immune responses against several HCV antigens, which could be an advantage compared to vaccine strategies focusing on only one branch of the immune response. We have already assessed a previous stage of our design in which the chimeric protein Eq1 contained only epitopes from $\mathrm{HCV}$ structural proteins. It was observed that immunization of $\mathrm{BALB} / \mathrm{c}$ mice with this protein in alum elicited a neutralizing antibody response against a heterologous HCV cell culture along with an IFN- $\gamma$-specific immune response [23]. However, obtaining a design with a broader epitope representation was still a pending task.

In the present work, the immunogenicity of the chimeric proteins EnvCNS3 and NS3EnvCo, containing selected conserved regions of $\mathrm{HCV}$ core, E1, E2 and NS3 antigens in combination with a recombinant HCV E2 protein (E2.680) was evaluated in BALB/c mice. This combination was of great interest, since the E2.680 protein has been shown previously to be highly immunogenic [24]. Also, the ability of the $\mathrm{CpG}$ oligodeoxynucleotide ODN39M to potentiate a functional cellular immune response against $\mathrm{HCV}$ antigens was assessed.

\section{Materials and methods}

\section{Cloning procedures}

Amplified DNA fragments encoding the core (aa110-160 or aa1-50), E1 (aa190-222), E2 (aa408-560), and NS3 (aa12301433 or aa1230-1341) proteins were cloned into pGEM-T Easy Vector. Afterwards, the fragments were consecutively inserted in plasmid pIME64k after digestion of the corresponding $\mathrm{T}$ vector with restriction endonucleases (Promega, USA), resulting in the final constructs pPNSEst2E1P1 and 
pPEstNSE1P1 for expressing the proteins NS3EnvCo and EnvCNS3, respectively.

\section{Plasmids}

The plasmid pIME64k, prevoiusly used as the expression vector of the chimeric protein Eq1, contains fragments of the HCV Core (aa 1-50), E1 (aa 180-22) and E2 (aa 408-540) proteins [23]. The pGEM-T Easy Vector System I (Promega, USA) was used for the cloning of PCR products.

\section{Artificial epitope}

Epitope P1 (amino acid sequence: LPEYVIMVKLPSRA), containing an HLA-DR13 and HLA-DR11 binding motive, was designed using the Rankpep, SYFPETHI and ProPred bioinformatics servers.

\section{Oligonucleotides and PCR}

To amplify the DNA regions of interest, PCR was performed using Taq Polymerase (Promega, USA) and a set of primers that were obtained from the Department of Chemical Synthesis (Center for Genetic Engineering and Biotechnology, Havana, Cuba) (Table 1). The PCR was performed for 30 cycles, with each cycle consisting of 1 minute at $95^{\circ} \mathrm{C}, 1$ minute at $65^{\circ} \mathrm{C}$, and 40 seconds at $72^{\circ} \mathrm{C}$, with a final extension step at $72^{\circ} \mathrm{C}$ for 5 minutes.

\section{Expression of recombinant chimeric proteins}

The E. coli GC366 ([F' lacI q, lacZ D M15 proAB] dam13:Tn9 D (lac-pro)) strain was employed for cloning and selection of recombinant plasmids and for the expression of recombinant proteins. E. coli cells transformed with plasmid were cultured aerobically at $37^{\circ} \mathrm{C}$ with shaking overnight in
Luria-Bertani medium or expression medium supplemented with $100 \mu \mathrm{g}$ of ampicillin per $\mathrm{mL}$. The expression medium consisted of M9 synthetic medium supplemented with 10 $\mathrm{mg}$ of casein hydrolyzate per $\mathrm{mL}, 10 \mathrm{mg}$ of glucose per $\mathrm{mL}$, $0.1 \mathrm{mM} \mathrm{CaCl}_{2}$, and $2 \mathrm{mM} \mathrm{MgSO}_{4}$ [25].

\section{Purification of recombinant proteins}

After growth in expression medium, the cells were harvested by centrifugation at $3500 \mathrm{~g}$ for 20 minutes and resuspended in disruption buffer (50 mM Tris- $\mathrm{HCl}, 5 \mathrm{mM}$ EDTA, $\mathrm{pH}$ 6.9). Cells were disrupted by ultrasound (IKA, Germany) with three cycles of $80 \mathrm{~Hz}$, one minute each, and one minute of resting on ice between cycles. After centrifugation at $7000 \mathrm{~g}$ for $10 \mathrm{~min}$, the insoluble fraction of the cell lysate was used for purification of the protein by a washed-pellet procedure. The insoluble fraction was washed with $50 \mathrm{mM}$ Tris-HCl buffer (pH 6.9) containing 1\% Triton X-100 and $5 \mathrm{mM}$ EDTA. The insoluble fraction was then washed with $50 \mathrm{mM}$ Tris-HCl, $5 \mathrm{mM}$ EDTA (pH 6.9). The recombinant chimeric proteins were solubilized with $8 \mathrm{M}$ urea in $50 \mathrm{mM}$ Tris- $\mathrm{HCl}(\mathrm{pH}$ 6.9). The soluble fraction was further purified by immobilized metal affinity chromatography (IMAC), eluting the chimeric proteins with $250 \mathrm{mM}$ imidazole and 8 $\mathrm{M}$ urea in $50 \mathrm{mM}$ Tris- $\mathrm{HCl}$ ( $\mathrm{pH} 8.7$ ). Chimeric proteins were refolded by gel filtration chromatography in a G-25 coarse matrix. The protein NS3EnvCo was refolded using a buffer containing $50 \mathrm{mM}$ Tris, $0.1 \mathrm{mM}$ EDTA and $5 \%$ glycerol $(\mathrm{pH}$ 8.7). For the EnvCNS3 protein, a buffer containing $200 \mathrm{mM}$ Tris and $0.1 \mathrm{mM}$ EDTA (pH 8.7) was used.

\section{Electrophoresis and Western blot analysis}

Samples were separated by SDS/PAGE (15\% gels) and stained with Coomassie brilliant blue R250 (Sigma, St. Louis, MO, USA). This procedure, as well as

Table 1 Primers used for amplification of selected regions of the genes encoding the HCV E2, core, NS3, and E1 proteins and the peptide P1 by PCR

\begin{tabular}{|c|c|c|}
\hline Region/ endonucleases & Sense primer & Antisense primer \\
\hline $\begin{array}{l}\text { E2 (408-560) } \\
\text { XbaI/HindIII/XhoI }\end{array}$ & 5'-TCTAGAAGTCAGAAAATCCA -3' & 5'- CTCGAGAAGCTTGAACCCAGTGCTATT-3' \\
\hline $\begin{array}{l}\text { Core }(110-160) \\
\text { HindIII/XhoI }\end{array}$ & 5'-AAGCTTACTGACCCCCGGCGTAG -3' & 5'- CTCGAGGTCCTCCAGAACCCGGA-3' \\
\hline $\begin{array}{l}\text { NS3 (1230-1433) } \\
\text { XbaI/EcoRI/XbaI }\end{array}$ & 5'- GCTCTAGATGCTCCCACTGGCAGCGGC-3' & 5'-CTCTAGAGAATTCAACGACGTCTCCGATAGT -3 \\
\hline $\begin{array}{l}\text { NS3 (1230-1341) } \\
\text { XhoI/XhoI }\end{array}$ & 5'- CTCGAGGCTCCCACTGGCAGCGG-3' & 5'- CTCGAGCGGCGCTCCAGCCGTCT -3' \\
\hline $\begin{array}{l}\text { E1 (190-222) } \\
\text { HindIII/EcoV/XhoI }\end{array}$ & 5'- AAGCTTGATATCTCCGCCTATGAGGTG-3' & 5’-AAGCTTCTCGAGCATGATCATGTCGTC-3' \\
\hline $\begin{array}{l}\text { P1 } \\
\text { Xhol/XhoI }\end{array}$ & 5'-TTACATCTCGAGCTGCCCGAGTACGTGATC-3' & 5-TTACATCTCGAGGGCGCGGCTGGGCAGCTT-3’ \\
\hline
\end{tabular}


immunodetection by Western blot was performed as described previously [23]. The recombinant protein Co.120 [26] was used as a positive control in both assays, since the antibody used for Western Blot (mAb SS-HepC.1) recognizes residues 5-35 of the HCV core protein.

\section{Animals and immunization protocols}

Pathogen-free female BALB/c mice, 6-8 weeks old (weighing 18-20 g), were purchased from Centro Nacional para la Producción de Animales de Laboratorio (Havana, Cuba) and used for this in vivo study. The housing, maintenance, care and ethics for analysis of animals were in compliance with institutional guidelines.

Eleven animals per group were injected in the quadriceps muscle either with a chimeric protein alone (20 $\mu \mathrm{g}$ of EnvCNS3 or NS3EnvCo); or with the protein combined with $\mathrm{E} 2.680(16.7 \mu \mathrm{g})$ in alum. The control groups received only alum. Doses were given at weeks 0, 2, 4 and 10.

In the same manner, eleven animals per group were immunized intramuscularly either with chimeric proteins combined with E2.680 ( $20 \mu \mathrm{g}$ of EnvCNS3 or NS3EnvCo/ $16.7 \mu \mathrm{g}$ of E2.680) in alum; or the same formulation with ODN39M added (20 $\mu \mathrm{g}$ of EnvCNS3 or NS3EnvCo/16.7 $\mu \mathrm{g}$ of E2.680/100 $\mu \mathrm{g}$ of ODN39M/alum). As negative controls, one group was injected with alum alone and the other was injected with alum and ODN39M. Doses were given at weeks 0,3 , and 6 (Table 2).

Two weeks after the final dose, blood samples were collected from the retro-orbital sinus of the mice. Also, five animals per group were euthanized and spleens were taken for analysis of the cellular immune response. The remaining mice were challenged with recombinant vaccinia virus encoding HCV structural proteins (vvRE) in order to evaluate the in vivo immune response.

\section{Antigens}

Recombinant protein E2.680 comprising amino acids 384 to 680 of the HCV polyprotein, was produced in Pichia pastoris cells and secreted into the culture supernatant in an N-glycosylated form [24]. NS3 recmbinant protein (aa 1192 to 1457 ) was produced in E. coli as inclusion bodies and purified using metal affinity chromatography by means of the $6 \mathrm{xHis}$ tag attached to the $\mathrm{C}$-terminus of the protein [27]. The sequences of both antigens were obtained from a genotype $1 \mathrm{~b}$ HCV Cuban isolate. The respective antigens were prepared as a single large batch and had undetectable endotoxin levels (threshold, 0.1 endotoxin units per $\mathrm{mL}$ ). Peptides containing CTL sequences from the HCV E2 and NS3 proteins (Table 3) were synthesized by the Department of Peptide Synthesis (Center for Genetic Engineering and Biotechnology, Havana, Cuba). Concanavalin A (ConA, Sigma-Aldrich, USA, $5 \mu \mathrm{g} / \mathrm{mL}$ ) was used as positive control for evaluation of the cellular immune response. Oligodeoxynucleotide $39 \mathrm{M}$, a fragment of DNA with CpG motifs used as an immune stimulator was synthesized by the Department of Chemical Synthesis (Center for Genetic Engineering and Biotechnology, Havana, Cuba). Sequence: ATCGACTCT CGAGCGTTCTCGGGGGACGATCGTCGGGGG [28].

\section{Detection of antibodies against HCV antigens and chimeric proteins}

To detect the presence of murine anti-HCV IgG antibodies, an endpoint dilution ELISA was carried out as described

Table 2 Protocols for immunization of BALB/C mice with chimeric proteins formulations

\begin{tabular}{|c|c|c|c|}
\hline Groups/formulations & Antigen quantities $(\mu \mathrm{g})$ & Immunization (weeks) & $\begin{array}{l}\text { Blood } \\
\text { extraction } \\
\text { (week) }\end{array}$ \\
\hline NS3EnvCo & 20 & $0,2,4,10$ & 12 \\
\hline NS3EnvCo/ E2.680 & $20 / 16.7$ & $0,2,4,10$ & 12 \\
\hline EnvCNS3 & 20 & $0,2,4,10$ & 12 \\
\hline EnvCNS3/ E2.680 & $20 / 16.7$ & $0,2,4,10$ & 12 \\
\hline Alum & - & $0,2,4,10$ & 12 \\
\hline Group/formulation & Antigen quantities $(\mu \mathrm{g})$ & Immunization (weeks) & $\begin{array}{l}\text { Blood } \\
\text { extraction } \\
\text { (week) }\end{array}$ \\
\hline NS3EnvCo/ E2.680 & $20 / 16.7$ & $0,3,6$ & 8 \\
\hline NS3EnvCo/ E2.680/ODN39M & $20 / 16.7 / 100$ & $0,3,6$ & 8 \\
\hline EnvCNS3/ E2.680 & $20 / 16.7$ & $0,3,6$ & 8 \\
\hline EnvCNS3/ E2.680/ODN39M & $20 / 16.7 / 100$ & $0,3,6$ & 8 \\
\hline Alum & - & $0,3,6$ & 8 \\
\hline
\end{tabular}


Table 3 CTL peptide sequences of HCV proteins E2 and NS3 used for cell stimulation in ELISPOT assay

\begin{tabular}{lll}
\hline HCV protein & Peptide code & Sequence \\
\hline E2 & A15P20 & VHRFNSSGCSDRMAS \\
& A15P21 & GPVYCFTPSPVVVGT \\
& A15P22 & YPYRLWHYPCTVNFT \\
& A15P23 & NCNDSLQTGFLAALF \\
& A15P24 & VPTYNWGENETDVLL \\
& A15P25 & TKVPAAYAAQGYKVL \\
NS3 & A15P26 & NPSVAATLGFGAYM \\
& A15P27 & DSTTILGIGTVLDQA \\
& A15P28 & HLIFCHSKKKCDELA \\
& A15P29 & AAYAAQGYKVLVLNP \\
\hline
\end{tabular}

previously [23]. Following the same protocol, we also assessed the presence of IgG1 and IgG2a antibody subclasses using horseradish-peroxidase-conjugated goat antimouse IgG1 and IgG2a diluted 1:15,000 and 1: 60,000, respectively (Sigma-Aldrich).

\section{Spleen cell isolation and cell proliferation assay based on carboxyfluorescein diacetate succinimidyl ester staining}

Spleen cells were removed from immunized and control mice two weeks after final immunization in order to assess the rate of cell proliferation. We performed this experiment as described previously [23, 29]. Spleen cells were stained with carboxyfluorescein diacetate succinimidyl ester (CFSE; Sigma) and stimulated with E2.680 and NS3 proteins ( $8 \mu \mathrm{g} /$ $\mathrm{mL}$ ). Cells incubated with medium alone were used as negative controls. ConA (Sigma, $5 \mu \mathrm{g} / \mathrm{mL}$ ) was used as a positive control. Proliferating cells were identified by flow cytometry. Results were analyzed and the frequencies of cell subsets were calculated using FlowJo software (TreeStar, Ashland, OR, USA). The stimulation index (SI) was calculated by dividing the frequency (\%) of proliferating splenocytes (CFSElow) in the presence of antigen by the frequency of proliferating splenocytes without antigen. The SI was considered to be positive when the SI was greater than 2.5.

\section{Enzyme-linked immunospot assay for detection of IFN- $\gamma$ secretion}

An enzyme-linked immune spot (ELISPOT) assay for detection of IFN- $\gamma$-releasing cells using proteins and CTL peptide stimulation was performed as described [30]. Briefly, two weeks after the last immunization, splenocytes from immunized and control mice were isolated and stimulated with E2.680, NS3, NS3Envco and EnvCNS3 proteins $(8 \mu \mathrm{g} / \mathrm{mL})$ and cytotoxic T lymphocyte (CTL)-related peptide pools (5 $\mu \mathrm{g} / \mathrm{mL}$ ), corresponding to HCV E2 and NS3 proteins, for five days. Spots were counted under a stereo microscope (A.EL. VIS 4-Plate ELISPOT Reader, Hannover, Germany) and using Image $\mathrm{J}$ software. The results were expressed as the number of spot-forming cells (SFC) per $10^{6}$ splenocytes, after subtraction of the baseline number of IFN- $\gamma$-producing cells. All values exceeding three times the number of splenocytes detected in the negative control for each group $\left(\mathrm{SFC} / 10^{6}\right)$ were considered positive.

\section{Detection of IL-4 and IFN- $\gamma$ secretion}

To detect IL-4 and IFN- $\gamma$ secretion into the cell culture supernatant, a cytokine sandwich ELISA was performed as described previously [23]. The concentration of the corresponding cytokine in the cell culture supernatant was calculated by interpolation on a standard curve, which was generated by serially diluting the cytokine standard, starting at $10,000 \mathrm{pg} / \mathrm{mL}$.

\section{Surrogate challenge model}

A surrogate challenge model assay was performed as described previously [31]. Five mice per group were challenged with $1 \times 10^{6}$ plaque-forming units (pfu) of vaccinia virus vvRE (expressing HCV structural proteins) by intraperitoneal injection. Mice were sacrificed 5 days after challenge. The results are expressed as the $\log$ arithm $(\log 10)$ of the virus titer in the ovaries of mice. Animals with viral loads at least one $\log 10$ less than the mean viral titer of vvRE detected in the control group mice were considered to have had a positive response.

\section{Statistical analysis}

GraphPad Prism version 5.00 statistical software (GraphPad Software, San Diego, CA, USA) was used to carry out statistical analysis. Normality was analyzed by the Shapiro-Wilk test, and homogeneity of variance was analyzed by using Bartlett's test. The Mann-Whitney U-test was used as a nonparametric test to compare the magnitude of the response between two groups. Comparisons of the magnitude of the responses among all groups were performed using one-way analysis of variance or the Kruskal-Wallis test, with Newman-Keuls or Dunn's multiple comparisons, respectively, as a post-test. Frequency comparisons between groups were performed by Fisher's exact test. Differences were considered significant for $P<0.05$. 


\section{Results}

\section{Cloning, expression and purification of chimeric proteins}

With the aim of generating chimeric proteins encompassing conserved selected regions of the $\mathrm{HCV}$ core, E1, E2 and NS3 antigens, plasmids pPNSEst2E1P1 and pPEstNSE1P1, expressing NS3EnvCo and EnvCNS3, respectively, were obtained as explained in Materials and methods. Additionally, the sequence corresponding to P1, an artificial $\mathrm{CD}^{+}{ }^{+} \mathrm{T}$-cell-specific epitope (aa sequence: LPEYVIMVKLPSRA) was included.

As shown in Figure 1, the proteins EnvCNS3 and NS3EnvCo were obtained at the expected molecular weight (approximately $60 \mathrm{kDa}$ and $50 \mathrm{kDa}$, according to their aa sequences), showing approximately $27 \%$ and $24 \%$ expression, respectively, among the total cellular proteins (ImageJ 1.46r, National Institutes of Health, USA) (Fig. 1a).

The proteins were purified by a combination of washedpellet procedures and metal chelating affinity chromatography (ion $\mathrm{Ni}^{2+}$ ) and refolded by size-exclusion chromatography up to approximately $80 \%$ purity (according to Image $\mathbf{J}$ software) (Fig. 1a, lanes 4 and 6). Western blotting of purified proteins revealed that the contaminant bands observed at higher molecular weight were chimeric protein aggregates.
The immunogenicity of chimeric proteins alone or in combination with E2.680 protein was evaluated in BALB/c mice. The mode of immunization, quantity, and time schedule used were based on previous experience obtained from the analysis of several hepatitis $C$ protein antigens [23, 29, 31, 32]. BALB/c mice were injected four times intramuscularly with the chimeric proteins alone $(20 \mu \mathrm{g})$ or mixed with the recombinant protein E2.680 $(16.7 \mu \mathrm{g})$ and adjuvanted with alum.

\section{Addition of E2.680 protein results in higher antibody titers against chimeric proteins}

The mean antibody titers against EnvCNS3, NS3EnvCo, E2.680 and NS3 in animals injected with chimeric proteins alone or in combination with E2.680 are shown in Figure 2. IgG antibody titers induced by chimeric proteins were also tested using a recombinant HCV NS3 protein [27]. This NS3 protein has $42 \%$ and $76 \%$ sequence identity to the corresponding fragment in EnvCNS3 and NS3EnvCo, respectively. As shown in Figure 2, high IgG antibody titers were induced against the chimeric proteins and NS3 for all groups. When EnvCNS3 and NS3EnvCo were combined with E2.680, a significant increase in antibody titer against the chimeric proteins was observed in the immunized groups (Fig. 2a and b) (one-way ANOVA with Newman-Keuls as a post-test, $p<0.05$ ). The addition of E2.680 also enhanced the antibody response against NS3 epitopes in mice immunized with EnvCNS3/E2.680 (Fig. 2d) (one-way ANOVA with Newman-Keuls as a post-test, $p<0.05)$. In the case (a)

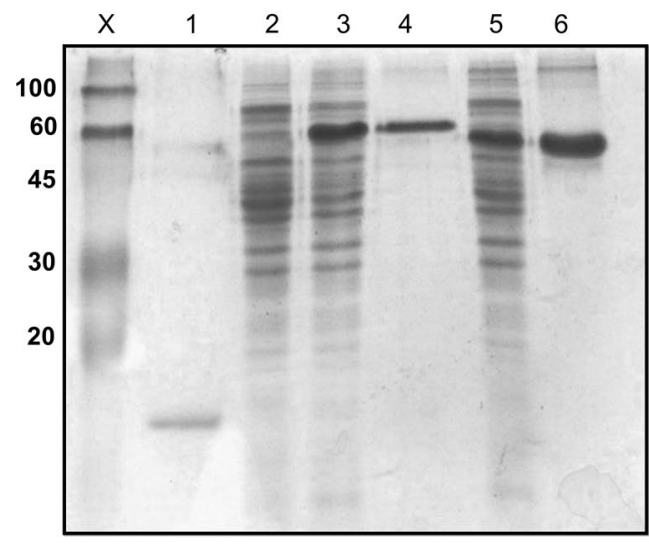

(b)

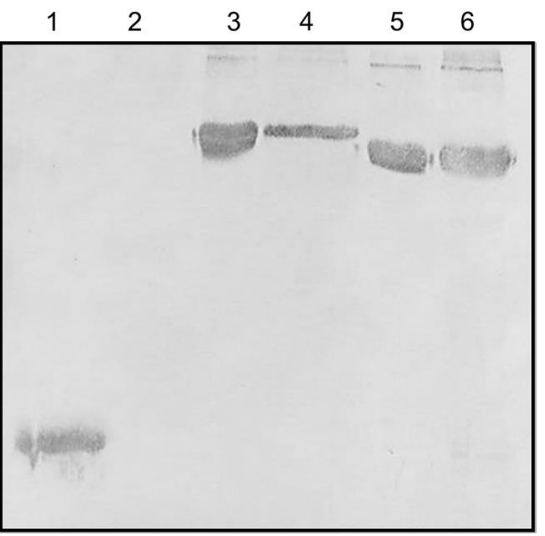

Fig. 1 Expression and purification of the chimeric proteins EnvCNS3 and NS3EnvCo. a. SDS-PAGE (12.5\% gel). b. Western blot using $\mathrm{mAb}$ SS-HepC. 1 that recognize the residues 5-35 of the HCV core protein. Approximately $7 \mu \mathrm{g}$ of protein was loaded in each well, excepting the control lane, in which $3 \mu \mathrm{g}$ of protein was loaded. Lanes: (1) Co.120 (recombinant HCV core protein) used as a positive control, (2) GC-366 non-transformed cells, (3) GC-366 cells transformed with pPEstNSE1P1 expressing EnvCNS3, (4) EnvCNS3 protein purified and refolded by metal chelating affinity chromatography (ion $\mathrm{Ni}^{+}$) and size-exclusion chromatography respectively, (5) GC-366 cells transformed with pPNSEst2E1P1, expressing NS3EnvCo, (6) NS3EnvCo protein purified and refolded by metal chelating affinity chromatography (ion $\mathrm{Ni}^{+}$) and size-exclusion chromatography, respectively, $(\mathrm{X})$ protein molecular weight markers (SigmaAldrich) 
Fig. 2 Total IgG antibody response against chimeric proteins EnvCNS3 (a), NS3EnvCo (b), E2.680 (c), and NS3 (d). Serum samples were collected from BALB/c mice 15 days after the last immunization and were analyzed by endpoint dilution ELISA. * (One-way ANOVA with Newman-Keuls as a post-test, $p<0.05$ ) denotes statistical differences for chimeric proteins combined with E2.680 (recombinant HCV E2 protein) compared to the formulations with the corresponding chimeric protein alone. The bars represent the standard deviation for each group (11 mice per group) (a)

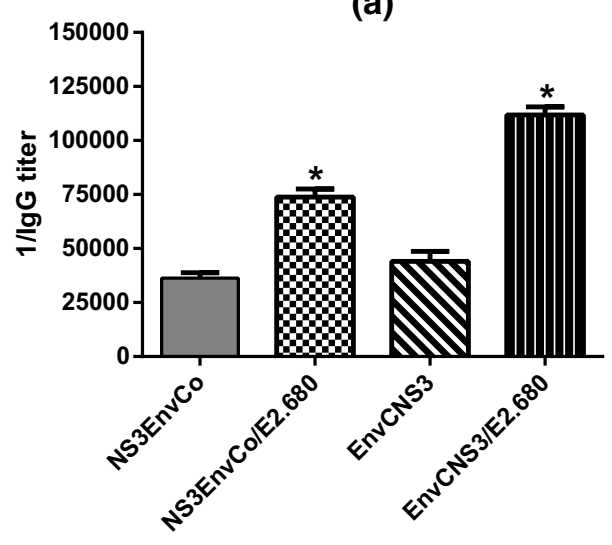

(c)

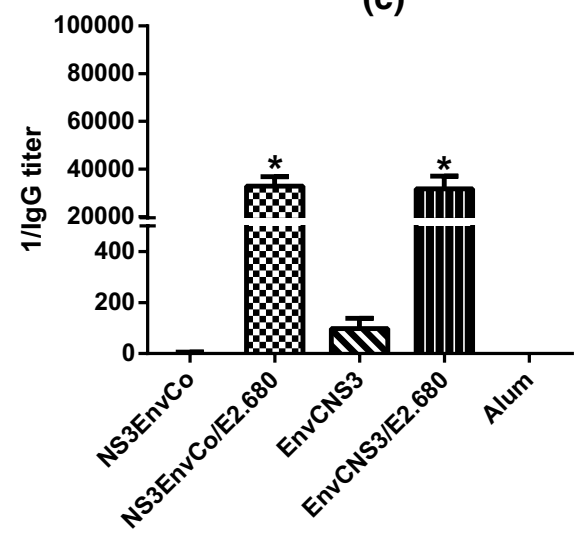

(b)

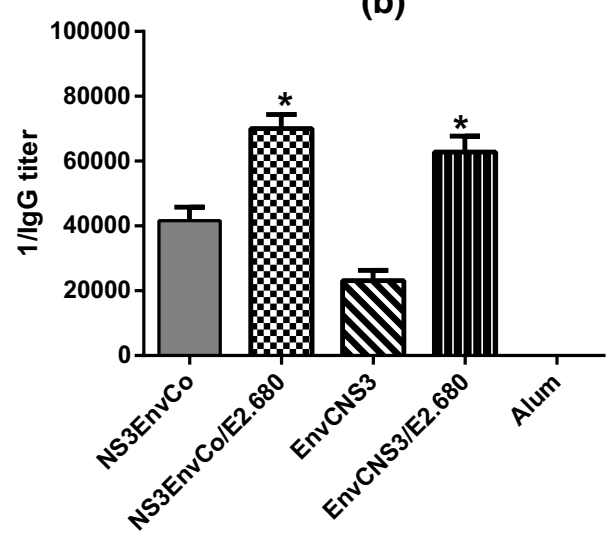

(d)

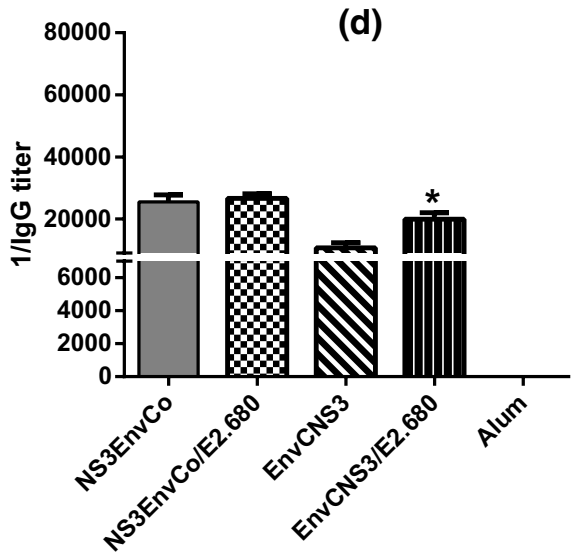

of the humoral response against the E2.680 protein, mice immunized with EnvCNS3 protein alone showed a positive antibody response with low titers in $50 \%$ of mice. On the other hand, no positive response was detected in the group immunized with NS3EnvCo alone. High IgG antibodies titers against E2.680 were only detected in the groups immunized with chimeric protein plus E2.680 (Fig. 2c).

\section{E2.680 protein enhances cellular immune response against chimeric proteins}

The interferon gamma (IFN- $\gamma)$-secreting cell response induced by the immunization with chimeric proteins alone or in combination with E2.680 was analyzed by enzymelinked immune spot assay (ELISPOT). Figure 3 a shows that immunization with chimeric proteins alone were not able to induce a positive IFN- $\gamma$ response. However, when the chimeric proteins were mixed with E2.680, significantly higher levels of IFN- $\gamma$-secreting cell response against all tested antigens were observed ( $p<0.01$, Mann-Whitney test).

A similar result was obtained when the cell proliferative response to $\mathrm{HCV}$ antigens was examined (Fig. 3b). For each antigen, the stimulation index was significantly higher in the groups immunized with chimeric proteins combined with E2.680 than in those injected with chimeric proteins alone ( $p<0.01$, Mann-Whitney test).

Additionally, the levels of the soluble cytokines IFN- $\gamma$ and IL-4 in cell culture supernatants were measured at the second week after the last immunization (Fig. 3c). A positive IFN- $\gamma$ response was observed in groups immunized with chimeric proteins in combination with E2.680 $(p<0.01$, Mann-Whitney test). However, no significant differences were detected in the levels of IL-4 (data not shown).

\section{Control of viral titer induced by chimeric proteins formulations combined with E2.680 protein}

To analyze the in vivo functionality of the cellular immune response induced by vaccination with chimeric proteins, a challenge experiment with vvRE (a recombinant vaccinia virus expressing HCV structural proteins) [33] was carried out. The immune response elicited by formulations with chimeric proteins alone was not able to protect mice against viral challenge. On the other hand, it was observed that the combination of chimeric proteins with E2.680 resulted in a drop of at least one log in the viral titer. However, this 
Fig. 3 Cellular immune responses against HCV antigens elicited in vaccinated $\mathrm{BALB} / \mathrm{c}$ mice two weeks after the last immunization. a. IFN- $\gamma$ secretory response to HCV antigens and chimeric proteins, tested by ELISPOT. The splenocytes from injected mice were separated and cultured for 5 days in the presence of $8 \mu \mathrm{g}$ of recombinant E2.680, NS3, EnvCNS3 and NS3EnvCo proteins per mL or medium alone. The data are shown as HCV-specific IFN- $\gamma$ spots per $10^{6}$ cells and represent mean values, determined in duplicate tests after subtracting the background value (without antigen), which were typically less than 5 spots. Positive value always exceeded twice the number of spots detected in the unstimulated cells for each group and at least 40 spots per million splenocytes. The number of spots for the alumimmunized group was always below 5 . The asterisks indicate that differences are statistically significant with respect to the control group (alum) and immunization with chimeric proteins alone (*, $p$ $<0.01$, Mann-Whitney test). b. The in vitro splenocyte proliferative response elicited in mice by chimeric proteins immunization, assayed by CFSE staining. Fifteen days after the last immunization, the splenocytes from injected mice were separated and individually stained with CFSE and cultured for 6 days in the presence of $8 \mu \mathrm{g}$ of recombinant E2.680, NS3, EnvCNS3 and NS3EnvCo proteins per mL or medium alone. Cells were analyzed by flow cytometry and CFSElow. Results are represented as the mean stimulation index (SI), which was calculated as the fold increase of stimulated versus unstimulated cell cultures. SI $\geq 3$ was considered positive (black line). The asterisks indicate that differences are statistically significant with respect to the control group (alum) and immunization with chimeric proteins alone $(*, p<0.01$, Mann-Whitney test). c. IFN- $\gamma$ secretion in spleen cell culture supernatant in vaccinated mice two weeks after last the immunization, tested by ELISA. Data are shown as cytokine concentration $(\mathrm{pg} / \mathrm{mL})$ determined in duplicate tests. The black line represents the cutoff value, defined as three times the concentration of unstimulated cells for each group. The asterisks indicate that differences are statistically significant with respect to the control group (alum) and immunization with chimeric proteins alone $\left(^{*}, p<0.01\right.$, Mann-Whitney test). The bars represent the standard deviation for each group (5 mice per group)

reduction in viral titer was only statistically significant for mice immunized with EnvCNS3/E2.680 ( $p<0.05$, KruskalWallis test with Dunn's multiple comparisons as a post-test) (Fig. 4).

\section{Adjuvant ODN39M induces higher IgG2a subclass titers when combined with NS3EnvCo chimeric protein}

In order to potentiate the functional T-cell immune response of chimeric proteins formulations in combination with E2.680, a new immunization schedule was carried out including adjuvant oligodeoxynucleotide 39M (ODN39M). This synthetic ODN contains unmethylated CpG motifs that are known to have an immunostimulatory effect (reviewed in reference 34).

Three intramuscular injections at three-week intervals with chimeric proteins mixed with E2.680 protein and adjuvanted with alum alone or with ODN39M were administered to BALB/c mice as described in Materials and methods. Adjuvant ODN39M was used because it was shown (a)

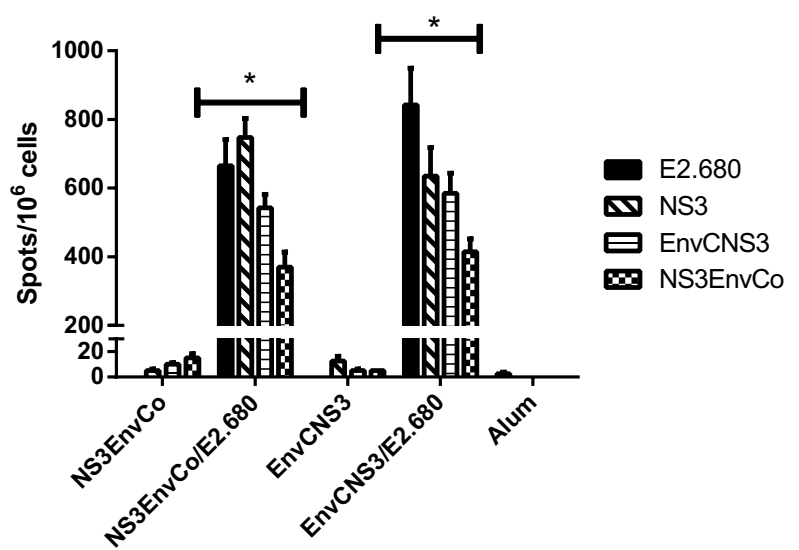

(b)

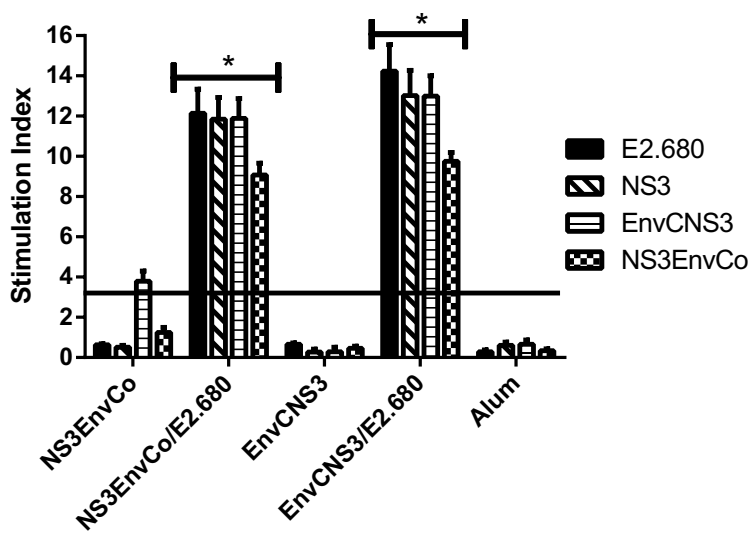

(c)

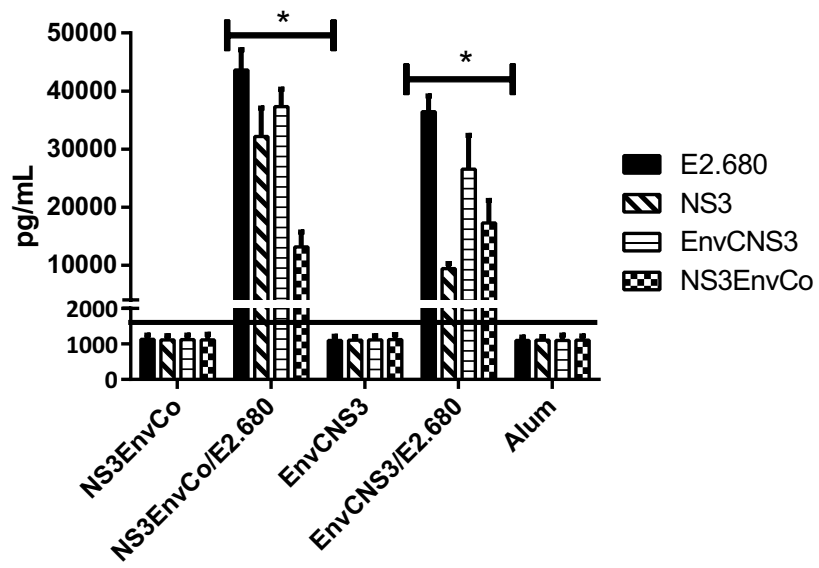

previously to skew the immune response towards a $\mathrm{T}$ helper 1 (Th1) pattern [28].

The IgG antibody response was determined using an ELISA end point dilution assay. High titers of $\mathrm{IgG}$ antibodies against chimeric proteins as well as E2.680 and NS3 were induced in all immunized groups, except controls (data not shown). 


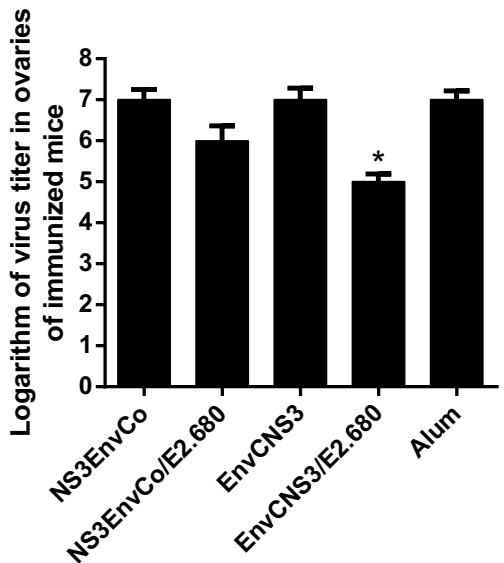

Fig. 4 Recombinant vaccinia virus titer after challenge of BALB/c mice with vvRE coding for structural region of HCV. Five mice per group, following the immunization schedule of $0,2,4,6$ and 10 weeks, were challenged at week 12 with $10^{6}$ pfu of recombinant vaccinia virus coding for HCV structural protein (vvRE) by intraperitoneal inoculation. The ovaries were collected 5 days after challenge. The bars indicate $\log _{10}$ of the mean viral titer. The asterisks indicate that differences are statistically significant with respect to alum $(*, p$ $<0.05$, Kruskal-Wallis test with Dunn's multiple comparisons as a post-test). The bars represent the standard deviation for each group (5 mice per group)

The IgG1 and IgG2a subclasses were also evaluated. In all groups, high titers of the IgG1 subclass against the chimeric proteins, E2.680 and NS3 were observed (Fig. 5 a, b, c and d). Interestingly, a significant increase in IgG2asubclass antibodies against all antigens in comparison with NS3EnvCo/E2.680/alum was detected when the formulation NS3EnvCo/E2.680/ODN39M/alum was used (one-way ANOVA with Newman-Keuls as a post-test, $p<0.05)$.

\section{ODN39M combined with NS3EnvCo favours a specific cell-mediated immune response able to protect mice after challenge with vvRE}

The HCV-specific IFN- $\gamma$-secreting cell response was evaluated by ELISPOT. Two weeks after the last immunization, spleen cells were extracted and stimulated with recombinant HCV structural and non-structural proteins. Also, cells were stimulated with pools of CTL peptides with sequences corresponding to epitopes from the HCV proteins E2 and NS3.

A broad IFN- $\gamma$-secreting response corresponding to splenocytes stimulated with $\mathrm{HCV}$ proteins was detected in all groups immunized with chimeric proteins (Fig. 6a). Notably, in the cells stimulated with CTL peptide pools, a positive response was observed only for the formulation $\mathrm{NS} 3 \mathrm{EnvCo} /$ E2.680/ODN39M/alum, showing significant differences compared to the control groups ( $p<0.01$, Mann-Whitney test) (Fig. 6b).
The in vivo functionality of the cellular immune response induced by chimeric proteins adjuvanted with ODN 39M was also assessed by challenge with vvRE (Fig. 6c). The viral titer in ovaries of mice injected with chimeric protein in combination with E2.680 was lower than the titer observed for their respective negative control, alum. Challenged mice immunized with NS3EnvCo/E2/ODN39M showed a significant reduction in viral titer compared to its control, alum/ ODN39M, and to the remaining groups ( $p<0.05$, KruskalWallis test with Dunn's multiple comparisons as a post-test). In this case all immunized animals were protected, and no vvRE was detected in the ovaries.

\section{Discussion}

Chronic hepatitis $\mathrm{C}$ infection is now treatable. However, the goal of eradicating this disease is still far from being accomplished. The high cost of therapy and the lack of accurate data about the $\mathrm{HCV}$-infected population worldwide are important factors hampering progress toward this important public-health goal [5]. Therefore, an affordable preventive vaccine against this infection is still needed.

Vaccine candidates evaluated in clinical trials have focused on inducing either humoral or cellular immune response against $\mathrm{HCV}$, with the later being more attractive for researchers. Immunization for the purpose of inducing a $\mathrm{CD}^{+} \mathrm{T}$ cell response has primarily targeted non-structural proteins such as NS3, NS4A-B and NS5A-B, since these antigens are well conserved across viral genotypes (reviewed in reference 35). Several immunization strategies have been assessed; in general these vaccines have managed to reduce viremia after HCV challenge in chimpanzee studies [36, 37]. However, no significant clinical impact has been observed. Experimental vaccines have been based on recombinant viral vectors derived from chimpanzee adenovirus (ChAd3) or the modified vaccinia virus Ankara strain (MVA) combining the coding region for the HCV non-structural proteins. The vaccines were tested in healthy volunteers using a heterologous prime/boost regimen that induced broad, potent, and sustained anti-HCV CD4 ${ }^{+}$and $\mathrm{CD}^{+}{ }^{+} \mathrm{T}$-cell responses [38]. However, when the same immunization procedure was tested in chronically infected individuals, the HCV-specific cellular response was significantly decreased, and the $\mathrm{CD} 4^{+} \mathrm{T}$-cell response could not be restored by vaccination. Also, the $\mathrm{T}$ cells that were induced were not cross-reactive with endogenous viral sequences and consequently did not significantly reduce the viral load [17].

Considering the above information, the development of a prophylactic vaccine candidate that enhances for enhancing both arms of the immune response could be an interesting strategy to assess. Thus, in the present work, the recombinant chimeric proteins EnvCNS3 and NS3EnvCo, 
(a)

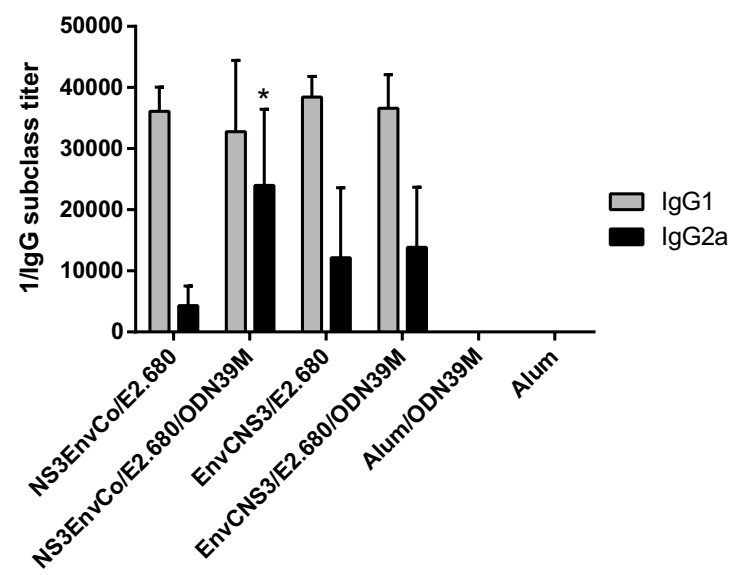

(c)

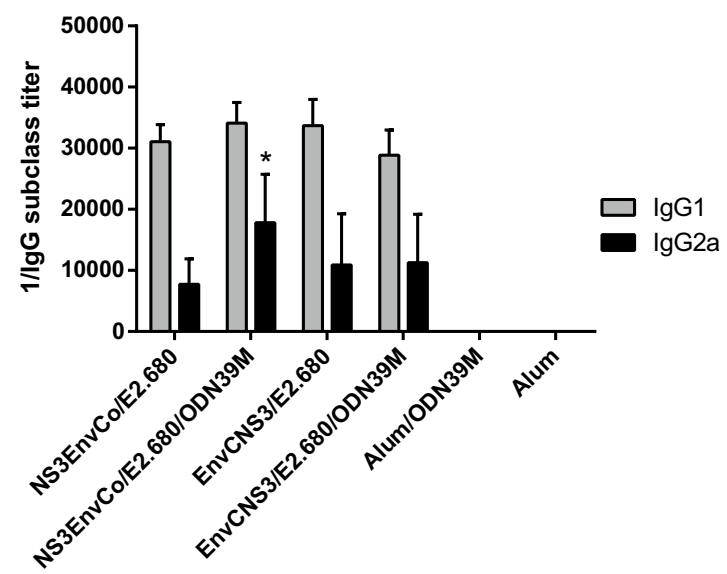

Fig. 5 IgG subclass response against chimeric proteins EnvCNS3 (a), NS3EnvCo (b), E2.680 (c) and NS3 (d) in BALB/c mice. Serum samples were collected 15 days after the last immunization and were analyzed by endpoint dilution ELISA assay. * (one-way ANOVA with Newman-Keuls as a post-test, $p<0.05$ ) indicates a statistical

composed of structural and non-structural antigens from $\mathrm{HCV}$, were generated, and their immunogenicity was evaluated in BALB/c mice. For this purpose, the correct selection of immunogenic and conserved epitopes for the design of chimeric antigens are critical for potentiating the immune response against $\mathrm{HCV}$ and avoiding viral escape [35]. This selection can be aided by the use of existing, well-characterized, computer-predicted consensus strains or sequences selected in silico to maximize the coverage of potential T- and B-cell epitopes and phylogenetically reconstructed HCV ancestral sequences $[39,40]$. The sequence for the design and cloning of the chimeric proteins EnvCNS3 and NS3EnvCo was obtained from a wellcharacterized Cuban genotype 1b HCV isolate (GenBank accession number AX683879) because more than $90 \%$ of $\mathrm{HCV}$-positive patients in Cuba are infected with genotype (b)

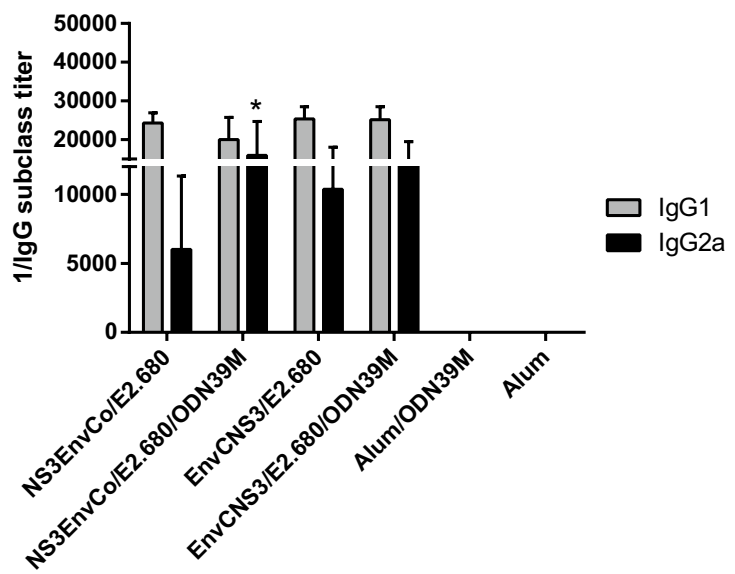

(d)

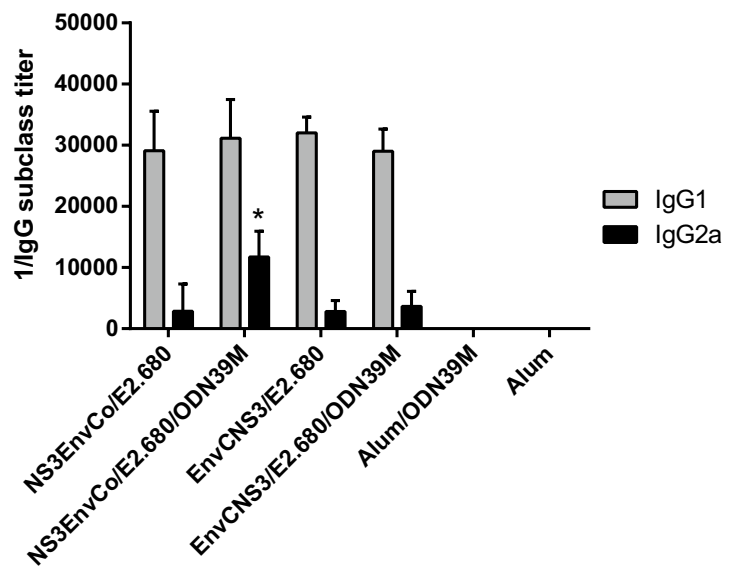

difference for NS3EnvCo/E2.680/ODN39M/alum compared to the formulation with NS3EnvCo/E2.680/Alum (without ODN39M) in all cases). The bars represent the standard deviation for each group (11 mice per group)

1b [41]. Also, the natural strain selected is very common in the population and contains several well-studied epitopes, some of which are highly conserved among HCV isolates of different genotypes [41].

The chimeric proteins contain selected epitopes from the HCV core, E1, E2 and NS3 proteins. These regions were selected to include epitopes specific for mouse and human B and/or T lymphocytes [23] that are also conserved among different viral genotypes [24, 26, 27, 42]. Moreover, sequences recognized by neutralizing antibodies were included on the E2 fragment [39]. This antigen design allows to reduce the number of proteins needed in order to broaden the immune response against HCV. Additionally, several protein regions that could lead to suppression of the immune response were avoided. In this case, hypervariable region 1 (HVR1) of E2 was excluded to facilitate induction 
Fig. 6 Cellular immune responses against HCV antigens elicited in vaccinated mice two weeks after the last immunization. The IFN- $\gamma$ secretion response against $\mathrm{HCV}$ recombinant proteins a. and cytotoxic T lymphocyte (CTL) peptides b. was tested by ELISPOT. The splenocytes from injected mice were separated and cultured for 5 days in the presence of $8 \mu \mathrm{g}$ of recombinant E2.680, NS3, EnvCNS3 and NS3EnvCo proteins per $\mathrm{mL}$, or $5 \mu \mathrm{g}$ of CTL peptides per $\mathrm{mL}$ or medium alone. The data are shown as HCV-specific IFN- $\gamma$ spots per $10^{6}$ cells and represent mean values determined in duplicate tests after subtracting the background value (without antigen), which were typically less than 5 . Positive values always exceeded twice the number of spots detected in the unstimulated cells for each group, and there were at least 40 spots per million splenocytes $(*, p<0.01$, Mann-Whitney test). c. Viral titer control in BALB/c mice after challenge with recombinant vvRE. Five mice per group, following the immunization schedule of 0,3 and 6 weeks, were challenged at week 8 with $10^{6}$ pfu of vvRE by intraperitoneal inoculation. The ovaries were collected 5 days after challenge. The bars indicate the $\log _{10}$ of the mean viral titer. The asterisks indicate that differences are statistically significant with respect to groups immunized with ODN39M, while " $\alpha$ " indicates a significant difference compared to mice immunized with alum. ( $p<0.05$, Kruskal-Wallis test with Dunn's multiple comparisons as a post-test). The bars represent the standard deviation for each group (5 mice per group)

of neutralizing antibodies that can recognize heterologous viral isolates [43].

The chimeric proteins EnvCNS3 and NS3EnvCo were shown to be immunogenic when administered to BALB/c mice and induced high titers of IgG antibodies against themselves and the NS3 protein. In contrast, the magnitude of the antibody response against E2.680 was low when the chimeric proteins were administered alone. Recombinant E2.680 protein, which was used as the capture antigen in the ELISA assay, can be obtained in a highly glycosylated and multimeric form in P. pastoris [24]. It is possible that the epitope on the chimeric proteins is hidden in E2.680 and is not detected by antibodies induced by the aforementioned formulations. In fact, Aguilar-Noriega et al. [23] demonstrated previously that Eq1, a chimeric protein containing the same E2 fragment (aa 408-540) as NS3EnvCo and EnvCNS3, was capable of inducing an anti-E2 antibody response. Interestingly, these antibodies showed neutralizing capacity against heterologous $\mathrm{HCVcc}$ (49.9\% of infectivity of HCVcc genotype 1al2a). Therefore, the results observed in the present work could be due to the characteristics of E2.680 protein used in the ELISA assay; rather than to a lack of immunogenicity of the selected E2 epitope (aa408 560 ) included in the chimeric proteins. The E2.680 protein is therefore not the best analytical tool for the assessment of antibody responses induced by immunization with chimeric proteins. Oppositely, high antibody titers were detected against the NS3 protein. The fragments corresponding to NS3 included in the chimeric design are highly represented on the recombinant NS3 protein used in the immunological tests: $42 \%$ for EnvCNS3 and 76\% for NS3EnvCo. Also, since NS3 was obtained from recombinant $E$. coli [27], no (a)

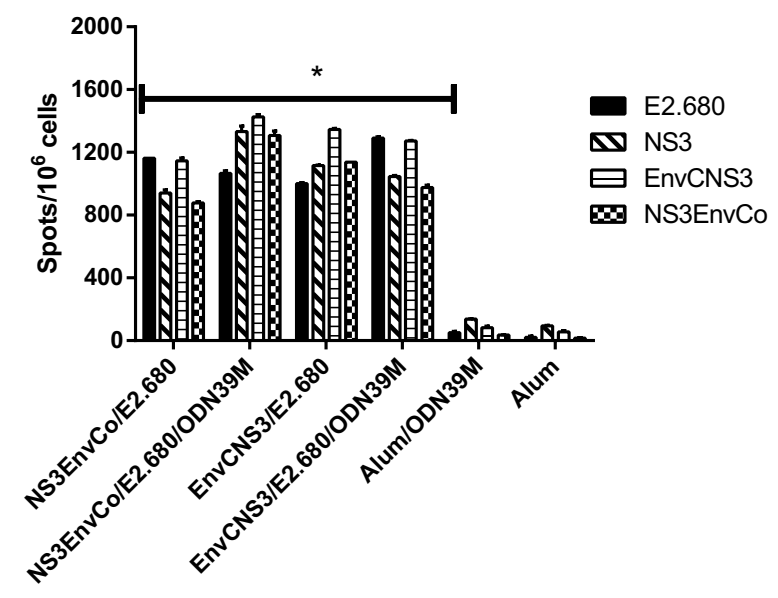

(b)

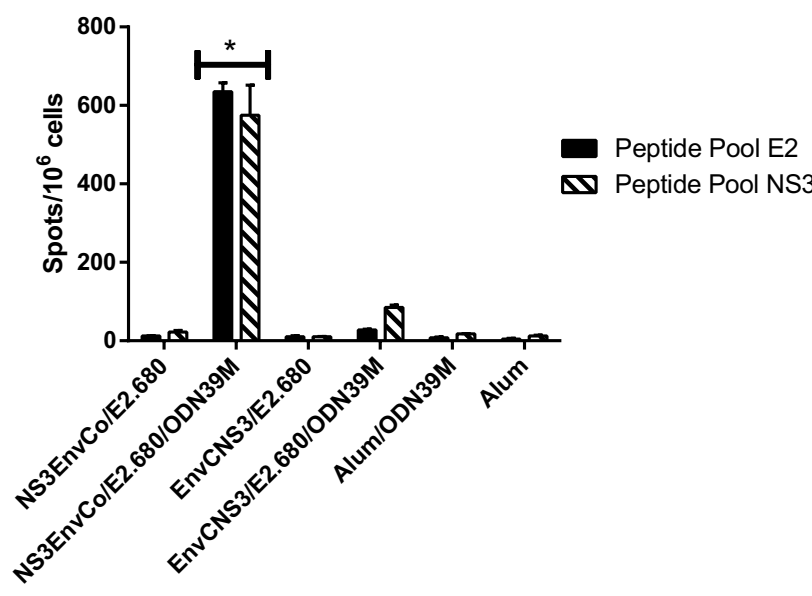

(c)

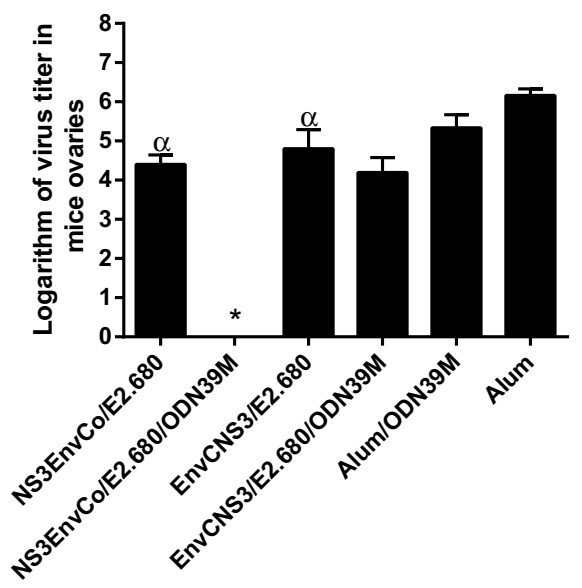

post-translational modifications masking important epitopes would be expected. Further experiments must be performed in order to characterize the immune response against each epitope contained on the chimeric proteins.

Immunization with chimeric proteins alone was not able to induce an IFN- $\gamma$-secreting response or a proliferative T 
cell response. The low immunogenicity of recombinant proteins has been described previously, and recombinant proteins appear to be poor targets for T cell induction [44]. However, formulations with an appropriate immune stimulator or delivery system for enhancing and directing the immune response have been used to overcome this problem. In fact, when chimeric proteins were mixed with E2.680 protein, a significant increase in the $\mathrm{IgG}$ antibody titer was observed against all antigens tested. This boosting effect was also evident in the cellular branch of the immune response, where chimeric protein/E2.680 formulations were able to enhance the IFN- $\gamma$ secretory response and proliferative response to E2.680, NS3, EnvCNS3 and NS3EnvCo epitopes. In previous studies, aggregated E2.680 was shown to induce strong $\mathrm{CD}^{+}{ }^{+}$and $\mathrm{CD}^{+} \mathrm{T}$ cell proliferation and was able to boost the $\mathrm{CD}^{+}$response against co-administered E1 and NS3 epitopes contained in the same formulation. Notably, this effect was not observed for E1 and NS3 antigens alone [31]. For these reasons, E2.680 was considered a key component of these vaccine formulations.

Experience with $\mathrm{HCV}$ vaccine design has shown that the nature of the antigens used and their association with appropriate adjuvants are crucial for epitope presentation and the induction of functional $\mathrm{T}$ cell immune responses [45, 46]. Consequently, the addition of ODN39M as an adjuvant to the formulation of chimeric proteins mixed with E2.680 was able to enhance the immune response induced against several antigens. Specifically for NS3EnvCo, a positive IFN- $\gamma$ secretory response against peptide pools containing $\mathrm{HCV}$ E2 and NS3 CTL-response-related epitopes was observed. Additionally, a significant increase in IgG2a-subclass antibodies was induced by the NS3EnvCo/E2.680/ODN39M formulation compared to the same formulation without ODN39M. Moreover, a preliminary analysis of this formulation using transmission electron microscopy suggested that NS3EnvCo, E2.680 and ODN39M form spherical particles (data not shown), which could improve antigen processing and the stimulation of immune cells response. A more detailed characterization of the formulation needs to be performed using techniques such as dynamic light scattering.

The effect of ODN39M on the immunogenicity of chimeric proteins observed in this work, agrees with that described for several protein vaccine candidates that include a CpG ODN as an adjuvant. The presence of CpG ODN in vaccines against influenza virus [47], anthrax [48], malaria [49] and Toxoplasma gondii [50] boosted the induction of the IgG2a subclass in mice. Similarly, a subclasses switch was observed for the response against hepatitis B surface antigen when adjuvanted with ODN1826, highlighting the importance of $\mathrm{CpG}$ motif on this molecule [51]. HCV vaccines containing ODN have also been tested. A recombinant immunogen containing epitopes from the HCV E1 protein and the E2 HVR1 was injected to mice in combination with alum and the ODN pUCpGs10. This formulation was able to induce high titers of cross-reactive $\mathrm{IgG}$ antibodies against peptides with sequences from the genotypes $1 \mathrm{a}, 1 \mathrm{~b}, 3 \mathrm{a}, 4 \mathrm{a}$ and $6 \mathrm{a}$. Moreover, a larger population of specific-antigensecreting B cells $\left(\mathrm{CD} 19^{+} ; \mathrm{CD} 38^{+}\right)$was induced [52]. In another study, a polyprotein containing the $\mathrm{HCV}$ core protein and the non-structural proteins NS3, NS4a, NS4b, NS5a and NS5b was tested in mice using a different delivery systems (alum, oil-in-water emulsion MF59 or poly(DL-lactide co-glycolide)) in the presence or absence of CpG ODN. The addition of ODN to the formulations resulted in an increase the IgG antibody titer against all of the antigens present in the polyprotein. Furthermore, it enhanced the anti-HCV $\mathrm{CD}^{+}{ }^{+} \mathrm{T}$ cell proliferative response [53].

The cellular component of the Th1 response induced by CpG ODN makes it a very suitable adjuvant for vaccines against viral infections (reviewed in reference 19). The activation of TLR9 (ODN's pattern recognition receptor) induces innate and adaptive immune responses characterized by the secretion of IFN- $\alpha$, IFN- $\gamma$, TNF- $\alpha$, IL- 12 , IL-6, among others, that leads to the differentiation of Th0 into Th1 [54-56]. The immune response in the Th1 context is characterized by the onset of a $\mathrm{CD} 8^{+}$cytotoxic $\mathrm{T}$ cell response that results in the elimination of infected cells [57, 58]. In the present work, evidence suggesting the induction of a Th1 response was obtained when the formulation NS3EnvCo/E2.680/ODN39M elicited an immune response that was protective against recombinant vaccinia virus coding for $\mathrm{HCV}$ structural proteins in all immunized mice. This result is in accordance with what has been reported by Murata et al. [59], using HCV-like particles that induced a cellular immune response in mice that was protective in a surrogate HCV challenge model based on vaccinia virus. Protection against challenge with recombinant vaccinia virus has been associated with the induction of a specific T-cellmediated immune response against $\mathrm{HCV}$ antigens, involving both $\mathrm{CD} 4^{+} \mathrm{T}$ cells, mainly as inducers, and $\mathrm{CD} 8^{+} \mathrm{T}$ cells as effectors for viral clearance [59]. It is possible that ODN39M has an important role in the induction of this functional anti$\mathrm{HCV}$ cellular immune response in vivo. Moreover, in previous studies, ODN39M has shown the ability to elicit an immune response that is able to protect mice against dengue virus (DENV) in a mouse model of DENV encephalitis when used as adjuvant in a protein vaccine candidate against this pathogen [28]. This result also confirms the importance of ODN39M in protein vaccine formulations.

Regarding the HCV-vaccinia challenge model used in this work, it should be noted that although valuable in demonstrating induction of protective immunity, it is a surrogate model that does not represent natural infection. In addition, the mechanism of clearance of vaccinia virus in mice (which occurs in ovaries) is likely to be different from that of $\mathrm{HCV}$ in humans. Nevertheless, this is a valid assay to consider in 
the context of a viral infection with very narrow tropism and the lack of accessible animal models.

Interestingly, in this work, the induction of a Th1 immune response was favoured when ODN39M was mixed with NS3EnvCo/E2.680, in contrast to the chimeric protein EnvCNS3. Given that E2.680 and ODN39M were present in each formulation, a plausible hypothesis could be that the difference lies in the structural features of the chimeric proteins. EnvCNS3 and NS3EnvCo were designed with different arrangements of $\mathrm{HCV}$ epitopes because we wanted to evaluate the immunogenicity and processing of $\mathrm{HCV}$ epitopes displayed in a new context. Regarding epitope selection for both chimeric proteins, it should be noted that NS3EnvCo contains a larger NS3 fragment (aa 1230-1433) than EnvCNS3 (aa 1230-1341). These 92 additional residues provide NS3EnvCo with several epitopes that have being described as possible B cell epitopes (aa 1349-1363), MHC class I T cell epitopes (aa 1360-1368 and aa 1394-1402) and MHC class II epitopes (aa 1344-1352). All of these sequences are conserved in more than $90 \%$ of HCV genotypes $[60,61]$. It is possible that ODN39M enhances the processing and presentation of these epitopes, potentiating the immune response elicited by NS3EnvCo. Additionally, T-cell responses against NS3 protein have been described previously in patients that recovered spontaneously from $\mathrm{HCV}$ infection and those who had a positive response to conventional therapy $[62,63]$. Moreover, an inverse correlation between NS3-specific $\mathrm{CD} 4{ }^{+} \mathrm{T}$-cell responses and viral load has been described [64]. In particular, studies in humans have demonstrated that a positive IFN- $\gamma$-secreting response against the NS3 protein is related to a decrease in viral load [65].

Overall, the NS3EnvCo/E2.680/ODN39M formulation might constitute an effective immunogen against $\mathrm{HCV}$ with potential for reducing the likelihood of immune escape and viral persistence. However, further experiments must be performed to study the immune response to remaining epitopes in the chimeric proteins originating from the $\mathrm{HCV}$ core and E1 proteins. Likewise, a deeper study investigating the induction of neutralizing antibodies and the contribution of each antigen to the priming of specific long-lasting $\mathrm{CD} 8^{+}$ and $\mathrm{CD} 4{ }^{+} \mathrm{T}$ cell response should be carried out.

Acknowledgements The authors would like to thank Lázaro Gil González, Alexis Musacchio Lasa, Tania Cárdenas Borrego and Ingrid Rodríguez for their valuable contribution to this work.

\section{References}

1. Gower E, Estes C, Blach S, Razavi-Shearer K, Razavi H (2014) Global epidemiology and genotype distribution of the hepatitis $C$ virus infection. J Hepatol 61:S45-S57
2. Pawlotsky JM, Feld JJ, Zeuzem S, Hoofnagle JH (2015) From non-A, non-B hepatitis to hepatitis $\mathrm{C}$ virus cure. $\mathrm{J}$ Hepatol 62:S87-S99

3. Zhang J, Nguyen D, Hu KQ (2016) Chronic hepatitis C virus infection: a review of current direct-acting antiviral treatment strategies. N Am J Med Sci (Boston) 9:47-54

4. Muir AJ, Naggie S (2015) Hepatitis C virus treatment: is it possible to cure all hepatitis $\mathrm{C}$ virus patients? Clin Gastroenterol Hepatol 13:2166-2172

5. Cox AL (2015) MEDICINE. Global control of hepatitis C virus. Science 349:790-791

6. Goossens N, Negro F (2014) Is genotype 3 of the hepatitis $C$ virus the new villain? Hepatology 59:2403-2412

7. Vermehren J, Park JS, Jacobson IM, Zeuzem S (2018) Challenges and perspectives of direct antivirals for the treatment of hepatitis C virus infection. J Hepatol 69:1178-1187

8. Badr G, Bedard N, Abdel-Hakeem MS et al (2008) Early interferon therapy for hepatitis $\mathrm{C}$ virus infection rescues polyfunctional, long-lived CD8+ memory T cells. J Virol 82:10017-10031

9. Dahari H, Feinstone SM, Major ME (2010) Meta-analysis of hepatitis $\mathrm{C}$ virus vaccine efficacy in chimpanzees indicates an importance for structural proteins. Gastroenterology 139:965-974

10. Lucas M, Ulsenheimer A, Pfafferot K et al (2007) Tracking virusspecific CD4+ T cells during and after acute hepatitis $\mathrm{C}$ virus infection. PLoS One 2:e649

11. Semmo N, Lucas M, Krashias G, Lauer G, Chapel H, Klenerman P (2006) Maintenance of HCV-specific T-cell responses in antibody-deficient patients a decade after early therapy. Blood 107:4570-4571

12. Logvinoff C, Major ME, Oldach D et al (2004) Neutralizing antibody response during acute and chronic hepatitis $\mathrm{C}$ virus infection. Proc Natl Acad Sci USA 101:10149-10154

13. Alvarez-Lajonchere L, Duenas-Carrera S (2012) Complete definition of immunological correlates of protection and clearance of hepatitis $\mathrm{C}$ virus infection: a relevant pending task for vaccine development. Int Rev Immunol 31:223-242

14. Raghuraman S, Park H, Osburn WO, Winkelstein E, Edlin BR, Rehermann B (2012) Spontaneous clearance of chronic hepatitis $\mathrm{C}$ virus infection is associated with appearance of neutralizing antibodies and reversal of T-cell exhaustion. J Infect Dis 205:763-771

15. Pestka JM, Zeisel MB, Blaser E et al (2007) Rapid induction of virus-neutralizing antibodies and viral clearance in a single-source outbreak of hepatitis C. Proc Natl Acad Sci USA 104:6025-6030

16. Abdel-Hakeem MS, Shoukry NH (2014) Protective immunity against hepatitis C: many shades of gray. Front Immunol 5:274

17. Swadling L, Halliday J, Kelly C et al (2016) Highly-immunogenic virally-vectored T-cell vaccines cannot overcome subversion of the T-cell response by HCV during chronic infection. Vaccines (Basel) 4:27

18. Nascimento IP, Leite LC (2012) Recombinant vaccines and the development of new vaccine strategies. Braz J Med Biol Res 45:1102-1111

19. Hanagata N (2012) Structure-dependent immunostimulatory effect of $\mathrm{CpG}$ oligodeoxynucleotides and their delivery system. Int J Nanomedicine 7:2181-2195

20. Bode C, Zhao G, Steinhagen F, Kinjo T, Klinman DM (2011) CpG DNA as a vaccine adjuvant. Expert Rev Vaccines 10:499-511

21. Beaumont E, Patient R, Hourioux C, Dimier-Poisson I, Roingeard P (2013) Chimeric hepatitis B virus/hepatitis C virus envelope proteins elicit broadly neutralizing antibodies and constitute a potential bivalent prophylactic vaccine. Hepatology 57:1303-1313

22. Sominskaya I, Skrastina D, Dislers A et al (2010) Construction and immunological evaluation of multivalent hepatitis B virus (HBV) core virus-like particles carrying HBV and HCV epitopes. Clin Vaccine Immunol 17:1027-1033 
23. Aguilar-Noriega D, Alvarez-Lajonchere L, Brown E et al (2014) A chimeric protein encompassing hepatitis $\mathrm{C}$ virus epitopes is able to elicit both humoral and cell-mediated immune responses in mice. Biotechnol Appl Biochem 61:627-636

24. Martinez-Donato G, Capdesuner Y, Acosta-Rivero N et al (2007) Multimeric HCV E2 protein obtained from Pichia pastoris cells induces a strong immune response in mice. Mol Biotechnol $35: 225-235$

25. Yero D, Pajon R, Niebla O et al (2006) Bicistronic expression plasmid for the rapid production of recombinant fused proteins in Escherichia coli. Biotechnol Appl Biochem 44:27-34

26. Alvarez-Obregon JC, Duenas-Carrera S, Valenzuela C, Grillo JM (2001) A truncated HCV core protein elicits a potent immune response with a strong participation of cellular immunity components in mice. Vaccine 19:3940-3946

27. Palenzuela D, Pedroso S, Roca J, Illareal G, Emos O, Eyes J (2006) A new NS3 recombinant protein shows improved antigenic properties for HCV diagnosis. Biotechnol Aplicada 23:94-98

28. Gil L, Marcos E, Izquierdo A et al (2015) The protein DIIIC-2, aggregated with a specific oligodeoxynucleotide and adjuvanted in alum, protects mice and monkeys against DENV-2. Immunol Cell Biol 93:57-66

29. Duenas-Carrera S, Alvarez-Lajonchere L, Cesar Alvarez-Obregon $\mathrm{J}$ et al (2002) Enhancement of the immune response generated against hepatitis $\mathrm{C}$ virus envelope proteins after DNA vaccination with polyprotein-encoding plasmids. Biotechnol Appl Biochem 35:205-212

30. Schmittel A, Keilholz U, Bauer S et al (2001) Application of the IFN-gamma ELISPOT assay to quantify $T$ cell responses against proteins. J Immunol Methods 247:17-24

31. Martinez-Donato G, Amador-Canizares Y, Alvarez-Lajonchere L et al (2014) Neutralizing antibodies and broad, functional $\mathrm{T}$ cell immune response following immunization with hepatitis $\mathrm{C}$ virus proteins-based vaccine formulation. Vaccine 32:1720-1726

32. Martinez-Donato G, Piniella B, Aguilar D et al (2016) Protective $T$ cell and antibody immune responses against hepatitis $C$ virus achieved using a biopolyester-bead-based vaccine delivery system. Clin Vaccine Immunol 23:370-378

33. Alverez-Lajonchere L, Gerra I, Amador-Cañizares Y et al (2007) Generation and characterization of recombinant vaccinia viruses expressing a hepatitis $\mathrm{C}$ virus Core protein, genotype $1 \mathrm{~b}$, individually or as a polyprotein. Biotecnología Aplicada 24:246-253

34. Hanagata N (2017) CpG oligodeoxynucleotide nanomedicines for the prophylaxis or treatment of cancers, infectious diseases, and allergies. Int J Nanomedicine 12:515-531

35. Ghasemi F, Rostami S, Meshkat Z (2015) Progress in the development of vaccines for hepatitis $\mathrm{C}$ virus infection. World J Gastroenterol 21:11984-12002

36. Folgori A, Capone S, Ruggeri L et al (2006) A T-cell HCV vaccine eliciting effective immunity against heterologous virus challenge in chimpanzees. Nat Med 12:190-197

37. Rollier CS, Paranhos-Baccala G, Verschoor EJ et al (2007) Vaccine-induced early control of hepatitis $\mathrm{C}$ virus infection in chimpanzees fails to impact on hepatic PD-1 and chronicity. Hepatology 45:602-613

38. Swadling L, Capone S, Antrobus RD et al (2014) A human vaccine strategy based on chimpanzee adenoviral and MVA vectors that primes, boosts, and sustains functional HCV-specific T cell memory. Sci Transl Med 6:261ra153

39. Burke KP, Munshaw S, Osburn WO et al (2012) Immunogenicity and cross-reactivity of a representative ancestral sequence in hepatitis C virus infection. J Immunol 188:5177-5188

40. Yusim K, Dilan R, Borducchi E et al (2013) Hepatitis C genotype 1 mosaic vaccines are immunogenic in mice and induce stronger T-cell responses than natural strains. Clin Vaccine Immunol 20:302-305
41. Gonzalez-Horta EE, Marante J, Amador-Canizares Y et al (2011) Analysis of hepatitis $C$ virus core encoding sequences in chronically infected patients reveals mutability, predominance, genetic history and potential impact on therapy of Cuban genotype $1 b$ isolates. Eur Rev Med Pharmacol Sci 15:1320-1327

42. Lorenzo LJ, Garcia O, Acosta-Rivero N et al (2000) Expression and immunological evaluation of the Escherichia coli-derived hepatitis $\mathrm{C}$ virus envelope $\mathrm{E} 1$ protein. Biotechnol Appl Biochem 32(Pt 2):137-143

43. Sabahi A, Uprichard SL, Wimley WC, Dash S, Garry RF (2014) Unexpected structural features of the hepatitis $\mathrm{C}$ virus envelope protein 2 ectodomain. J Virol 88:10280-10288

44. Seong YR, Choi S, Lim JS, Lee CH, Lee CK, Im DS (2001) Immunogenicity of the E1E2 proteins of hepatitis C virus expressed by recombinant adenoviruses. Vaccine 19:2955-2964

45. Cox JC, Coulter AR (1997) Adjuvants-a classification and review of their modes of action. Vaccine 15:248-256

46. Karch CP, Burkhard P (2016) Vaccine technologies: from whole organisms to rationally designed protein assemblies. Biochem Pharmacol 120:1-14

47. Wu F, Yuan XY, Li J, Chen YH (2009) The co-administration of CpG-ODN influenced protective activity of influenza M2e vaccine. Vaccine 27:4320-4324

48. Gu M, Hine PM, James JW, Giri L, Nabors GS (2007) Increased potency of BioThrax anthrax vaccine with the addition of the C-class CpG oligonucleotide adjuvant CPG 10109. Vaccine 25:526-534

49. Coban C, Ishii KJ, Stowers AW, Keister DB, Klinman DM, Kumar N (2004) Effect of CpG oligodeoxynucleotides on the immunogenicity of Pfs 25, a Plasmodium falciparum transmission-blocking vaccine antigen. Infect Immun 72:584-588

50. Sanchez VR, Pitkowski MN, Fernandez Cuppari AV et al (2011) Combination of CpG-oligodeoxynucleotides with recombinant ROP2 or GRA4 proteins induces protective immunity against Toxoplasma gondii infection. Exp Parasitol 128:448-453

51. Davis HL, Weeratna R, Waldschmidt TJ, Tygrett L, Schorr J, Krieg AM (1998) CpG DNA is a potent enhancer of specific immunity in mice immunized with recombinant hepatitis B surface antigen. J Immunol 160:870-876

52. Zhan N, Xiu BS, Wang GH et al (2011) Enhancement of humoral immunity in mice by coupling pUCpGs10 and aluminium to the HCV recombinant immunogen. Virol J 8:507

53. Vajdy M, Selby M, Medina-Selby A et al (2006) Hepatitis C virus polyprotein vaccine formulations capable of inducing broad antibody and cellular immune responses. J Gen Virol 87:2253-2262

54. Krieg AM (2002) CpG motifs in bacterial DNA and their immune effects. Annu Rev Immunol 20:709-760

55. Gursel M, Verthelyi D, Gursel I, Ishii KJ, Klinman DM (2002) Differential and competitive activation of human immune cells by distinct classes of $\mathrm{CpG}$ oligodeoxynucleotide. J Leukoc Biol $71: 813-820$

56. Hartmann G, Weeratna RD, Ballas ZK et al (2000) Delineation of a $\mathrm{CpG}$ phosphorothioate oligodeoxynucleotide for activating primate immune responses in vitro and in vivo. J Immunol $164: 1617-1624$

57. Krieg AM (2006) Therapeutic potential of Toll-like receptor 9 activation. Nat Rev Drug Discov 5:471-484

58. Rothenfusser S, Hornung V, Ayyoub M et al (2004) CpG-A and $\mathrm{CpG}-\mathrm{B}$ oligonucleotides differentially enhance human peptidespecific primary and memory CD8+ T-cell responses in vitro. Blood 103:2162-2169

59. Murata K, Lechmann M, Qiao M, Gunji T, Alter HJ, Liang TJ (2003) Immunization with hepatitis $C$ virus-like particles protects mice from recombinant hepatitis $\mathrm{C}$ virus-vaccinia infection. Proc Natl Acad Sci USA 100:6753-6758 
60. Naeem A, Waheed Y (2017) Sequence analysis of hepatitis C virus nonstructural protein 3-4A serine protease and prediction of conserved B and T cell epitopes. Biomed Rep 7:563-566

61. Ikram A, Zaheer T, Awan FM et al (2018) Exploring NS3/4A, NS5A and NS5B proteins to design conserved subunit multiepitope vaccine against HCV utilizing immunoinformatics approaches. Sci Rep 8:16107

62. Vertuani S, Bazzaro M, Gualandi G et al (2002) Effect of interferon-alpha therapy on epitope-specific cytotoxic $\mathrm{T}$ lymphocyte responses in hepatitis C virus-infected individuals. Eur J Immunol 32:144-154

63. Drane D, Maraskovsky E, Gibson R et al (2009) Priming of CD4+ and CD8+ T cell responses using a HCV core ISCOMATRIX vaccine: a phase I study in healthy volunteers. Hum Vaccin $5: 151-157$
64. Rosen HR, Ribeiro RR, Weinberger L et al (2002) Early hepatitis $\mathrm{C}$ viral kinetics correlate with long-term outcome in patients receiving high dose induction followed by combination interferon and ribavirin therapy. J Hepatol 37:124-130

65. Habersetzer F, Honnet G, Bain C et al (2011) A poxvirus vaccine is safe, induces T-cell responses, and decreases viral load in patients with chronic hepatitis C. Gastroenterology 141:890-899

Publisher's Note Springer Nature remains neutral with regard to jurisdictional claims in published maps and institutional affiliations. 